\title{
Ruptures, repairs, and reflections: contributions of Jeremy Safran
}

\author{
Lisa Wallner Samstag, ${ }^{1}$ J. Christopher Muran ${ }^{2,3}$ \\ ${ }^{1}$ Department of Psychology, Long Island University, Brooklyn; ${ }^{2}$ Gordon F. Derner School of Psychology, Adelphi University, Garden \\ City; ${ }^{3}$ Mount Sinai Beth Israel Psychotherapy Research Program, Mount Sinai School of Medicine, New York, NY, USA
}

\begin{abstract}
Jeremy D. Safran's contributions to our understanding of the complexities of the therapeutic relationship, and its role in the process of patient change in psychotherapy, have been profound. In this paper, we briefly summarize the evolution of his thinking about the alliance and highlight how his ambivalence about this construct contributed to his seminal work delineating rupture resolution models, defined as negotiated intersubjective processes between patient and therapist that are the very essence of the therapeutic process for some patients. Responding to strains in the alliance throughout the rupture resolution process is critical and is an aspect of the treatment model that trainees find most challenging. A clinical example is included to illustrate how Jeremy's attempts at metacommunicating about his experience with a frustrated patient initiated a productive shift in the process that also contributed to additional ruptures, requiring a simultaneous focus on the strained alliance.
\end{abstract}

Key words: Alliance; Alliance ruptures; Metacommunication.

\section{Introduction}

It is an honor to be invited to contribute to this special issue on the work of Jeremy D. Safran. While his death remains a painful reality that is still difficult to accept, we

Correspondence: Lisa Wallner Samstag, Department of Psychology, H-807, Long Island University, 1 University Plaza, Brooklyn, NY 11201, USA.

Tel.: 212.633.1615 - Fax: 718.488.1164.

E-mail: lisa.samstag@liu.edu

Citation: Samstag, L. W., \& Muran, J. C. (2019). Ruptures, repairs, and reflections: contributions of Jeremy Safran. Research in Psychotherapy: Psychopathology, Process and Outcome, 22(1), 7-14. doi: 10.4081 /ripppo.2019.376

Contributions: LWS conceived of the idea and wrote the majority of the manuscript; JCM provided feedback on the initial idea and edited the written draft, helping to expand on the ideas presented with his own contributions, including relevant citations.

Conflict of interest: the authors declare no potential conflict of interest.

Funding: none.

Received for publication: 18 January 2019.

Revision received: 11 March 2019.

Accepted for publication: 11 March 2019.

This work is licensed under a Creative Commons Attribution NonCommercial 4.0 License (CC BY-NC 4.0).

CCopyright L.W. Samstag and J.C. Muran, 2019

Licensee PAGEPress, Italy

Research in Psychotherapy:

Psychopathology, Process and Outcome 2019; 22:7-14

doi:10.4081/ripppo.2019.376 hope our paper, along with those of our colleagues, serves to celebrate and commemorate aspects of his tremendous contributions to the field of psychotherapy. We chose to highlight Jeremy's work on the therapeutic alliance and his contributions to our understanding of the process of change, what we consider to be the most influential of all of his many interests. Since we both worked closely with Jeremy over the past 30 years, we hope our reflections carry a personal quality as well.

\section{Beginning at the Clarke Institute of Psychiatry}

From 1986 until 1990, Jeremy was the Director of the Cognitive Therapy Unit at the Clarke Institute of Psychiatry in Toronto, with a dual appointment at the University of Toronto. He hired both of us to join his clinical research team: Lisa, in 1988 as the unit psychometrist, and Chris, in 1989, as a post-doctoral fellow. This was a small mental health research center within the hospital, treating outpatients with a radical (for its time) experimental model of time-limited psychotherapy that extended traditional cognitive therapy to address emotion and the therapeutic relationship in innovative ways (Greenberg \& Safran, 1986; Muran, Segal, Samstag, \& Crawford, 1994; Safran, 1990a, 1990b; Safran \& Segal, 1990/1996; Safran \& Wallner, 1991). The Cognitive Therapy Unit was an intellectually stimulating place where there were typically more clinical researchers around than patients, all engaged in intense discussion about how and why the alliance functioned as part of the change process. It was characteristic of Jeremy to push the envelope, to challenge accepted ideas as a way to deepen understanding of phenomena and move the field forward, in this case, the processes of change in cognitive therapy. The Cognitive 
Therapy Unit became the breeding ground for Jeremy's ideas about the importance of moments when the patient and therapist did not seem to be on the same page, not fully agreeing on what might be helpful. A steady stream of graduate students and visiting scholars attended our weekly research meetings, both learning from Jeremy and contributing to the ongoing, fruitful clinical discussions and psychotherapy process-outcome studies in which we were engaged. Jeremy was a welcoming figure-head and often held get-togethers in his charming home in the Danforth area, where heady debates were enhanced with excellent wine and food.

One of the highlights for us while at the Clarke Institute was observing Jeremy conducting therapy. Behind a one-way mirror, we witnessed Jeremy's early efforts to grapple with questions about the role of the therapeutic relationship in this new version of cognitive therapy. Manualized treatments with adherence checklists were becoming popular among researchers as a way to operationalize and teach the skills, as well as to statistically control for differences among therapists' use of those skills in outcome studies. However, adherence scales did not typically include patients' responses to therapists' prescribed interventions or descriptions of what to do when the prescribed interventions did not work as expected, such as in the context of a strained alliance. Jeremy's meta-level emphasis on the shifts in a patient's emotional responsiveness to what the therapist offered was a radical departure from the models that emphasized strict technical adherence. Here, he was particularly influenced by the work of Hans Strupp and the results of the Vanderbilt I study (Strupp \& Hadley, 1979) in considering the challenges of working productively with patients' hostility and ensuing negative therapeutic process. In this work, the therapeutic relationship was operationalized as the quality of interpersonal behaviors (e.g., intersecting dimensions of affiliation and interdependence on the interpersonal circumplex) rather than as a distinct alliance construct (Strupp, 1980). Jeremy found this model compelling and it contributed to his ambivalence about the need for a separate alliance construct.

\section{Negotiating ambivalence about the alliance construct}

Understanding the alliance in tandem with alliance ruptures, specific types of negative processes, was the heart of the work at the Clarke Institute in those days (Safran, 1993; Safran, Crocker, McMain, \& Murray, 1990) and became the foundation for the psychotherapy Jeremy and Chris subsequently developed, called Brief Relational Therapy (Safran \& Muran, 2000). Jeremy liked Bordin's (1979) conceptualization of the alliance construct, a reformulation of early psychoanalytic descriptions of the therapeutic relationship that tended to focus on a patient's transference, rather than the product of mutual influence from both patient and therapist. This al- liance was a prerequisite to effective treatment and was defined as a patient's positive transference (e.g., Freud's unobjectionable positive regard, 1912, and Sterba's rational transference, 1934, 1940), then as a basic trust that reflected early development and maternal influences espoused by the British Object Relations school (Balint, 1968; Winnicott, 1965) as well as a more reality-oriented adaptation to one's environment considered by ego psychologist (e.g., Freud, 1936; Hartmann, 1958), each consistent with the particular orientation's proposed process of therapeutic change. Alliance identified as a component of the therapeutic relationship that was somewhat distinct from the transference (Greenson, 1967) allowed for greater flexibility in responding to the needs of individual patients.

According to Bordin's (1979) transtheoretical concept, the quality and strength of the alliance depended on the degree to which a patient and therapist agreed upon the particular therapeutic activities or tasks that would lead to the amelioration of the problems that brought the patient to treatment in the first place (i.e., the treatment objectives or goals they agreed to work on), mitigated by the relational bond developed between them. Bordin's multidimentional alliance highlighted the interdependence of therapy-specific technique factors and relationship factors. Although a patient will find some activities more or less helpful depending on their own personality styles and capabilities, those who feel understood and respected by their therapists are more trusting and willing to do the work they need to do to alleviate their distress, as well as to negotiate any disagreements about the tasks and goals that emerge, further mediating the quality of the relational bond (Bordin, 1994). Jeremy carefully emphasized the distinction between collaboration and negotiation, describing how a patient's agreement with a therapist could, for instance, mask a subtly defensive, unconscious compliance (e.g., a withdrawal rupture). His ambivalence, thus, was rooted in considering ruptures as more or less distinct from the alliance construct by respecting how such particular interpersonal patterns that transpired between the patient and therapist contributed to new and transformative experiences. Rupture experiences could be more or less intense and highlighted that there was always some degree of tension in the relationship between the patient and therapist.

This dynamic formulation of the therapeutic relationship and assumption that ongoing negotiation between patient and therapist was essential to the process, placed an important focus on identifying and resolving ruptures as a key component of lasting change: "At a deeper level, it taps into fundamental dilemmas of human existence, such as the negotiation of one's desires with those of another, the struggle to experience oneself authentically as a subject while at the same time recognizing the subjectivity of the other, and the tension between the need for agency versus relatedness" (Safran \& Muran, 2000; p. 15). In 
other words, the relational negotiation, with contributions from both patient and therapist, was the treatment. In this regard, he tapped into themes associated with intersubjectivity and articulated in contemporary relational psychoanalysis (Aron, 1996; Benjamin, 1990; Pizer, 1998).

Interestingly, Jeremy remained ambivalent about the alliance construct throughout the course of his work and at times, wondered if it had perhaps outlived its usefulness (Safran \& Muran, 2000, 2006). On the one hand, he valued the importance of the unique human aspects both patient and therapist brought to sessions, appreciating how different tasks placed different demands on each of them, such that the meaning of any technical intervention could be understood only within the context of the particular therapeutic dyad and particular therapeutic relationship. As Hatcher (2010, p. 12) described it, patients and therapists each have their own "internal working alliance models" of what good collaborative work should be like, marking "the starting point for their negotiation of the alliance". Thus, understanding the alliance as a distinct construct that was foundational to productive therapeutic work and enabled therapists to respond flexibly to the needs of individual patients, was critical to Jeremy's thinking about the process of change.

On the other hand, with productive work conceptualized as the ongoing moment-to-moment negotiation of treatment tasks and goals, Jeremy also understood the alliance construct to be unnecessary as a distinct entity. One of his earliest inspirations was the work of Harry Stack Sullivan, whose interpersonal theory he integrated with the cognitive behavioral therapy of the time, and was a model that did not consider the therapeutic relationship as a distinct agent of change (Safran, 1984a; 1984b). Sullivan was attuned to his patients' anxiety and the subtle shifts that occurred throughout sessions, focused on helping to regulate and manage that anxiety as a way to maintain the therapeutic situation. This is a striking parallel to the rupture-repair cycles that were formulated and empirically supported as paths towards a patient's experience and awareness of different relational possibilities (Safran \& Muran, 1996; Safran, Muran, \& Samstag, 1994; Safran, Muran, Samstag, \& Stevens, 2002). Indeed, these intersubjective negotiations between a patient and therapist in developing and maintaining the therapeutic relationship, and the patient's emerging experience of a new and constructive connection with the therapist, were considered the "very essence of the change process" (Safran \& Muran, 2000; p. 13).

Unlike Sullivan, who saw the therapist as both a participant and observer who could, to some degree, stand outside of the interpersonal field and be objective in order to shed light on the patient's experience, Jeremy understood the therapist as essentially embedded within the interpersonal matrix and never able to fully step outside of the enactment. This idea that the patient and therapist are both contributing to unconscious mutual influences, or en- actments, is more consistent with contemporary interpersonalists (Levenson, 1992; Stern, 1997). In this way, ruptures - as opportunities to experience unique interpersonal interactions - are independent of a concept of the alliance.

Ultimately, in spite of these conceptual problems with the alliance construct, Jeremy held onto it as relevant because as an overarching, meta-level concept, it continued to provide a useful, unifying framework for therapists to guide their choice of intervention no matter what the treatment orientation. It had also been reliably demonstrated as an important, albeit small, predictor of overall outcome from a research perspective. However, correlations between alliance and outcome "in the area of .25 (approximately $6 \%$ of the outcome variance)", while reliable, "do not indicate a whopping effect" (Safran \& Muran, 2006; p. 286), suggesting other factors needed to be accounted for. From an alliance perspective, alliance ruptures are defined as a breakdown in the collaboration between patient and therapist (e.g., patient is hesitant to try a task the therapist is suggesting or is directly critical of the therapist). The operationalization of patient-therapist unconscious enactments as ruptures emerged, in part, from Jeremy's ambivalence about the alliance construct, and that tension between the two conceptualizations of the role of the therapeutic relationship further underscored its dynamic and complex nature. The idea that there was movement back and forth, both experientially and conceptually, from the point at which the need for the alliance became superfluous, was, in itself, an intriguing development in thinking about the process of change.

\section{Considering ruptures in the therapeutic alliance}

This dialectical way of thinking about the alliance as both necessary and unnecessary, as figure and ground - was reflected in Jeremy's definitions of alliance ruptures. He preferred the broader conceptualization of ruptures as negative turns in the quality of the therapeutic relationship as a dimension of the larger communication patterns evident between the patient and therapist - how they were communicating and interacting - rather than the more narrowly defined downward shift in the alliance itself (e.g., disagreement about a particular therapeutic task) as this lead more directly to the end goal of a patient developing the capacity for true emotional intimacy and authentic relatedness, the ability to experience self and others more fully as subjects (Benjamin, 1990). The concept of a rupture is distinct from the transference because ruptures always include contributions from both the patient and the therapist. This also extended Bordin's (1979) emphasis on collaboration between the patient and therapist and the negotiation of the working part of the relationship more narrowly.

The distinction between withdrawal ruptures (i.e., the patient disconnects from the self or some aspect of the work) and confrontation ruptures (i.e., the patient explic- 
itly expresses dissatisfaction with the therapist or some aspect of the treatment) was made based on observable behavioral and linguistic markers, and was important from a research perspective because different resolution processes were documented (Safran \& Muran, 1996, 2000). Again, the importance of both negotiation and collaboration as central to the change process is highlighted here, considering how patients and therapists each contribute to negative processes or relational configurations (Mitchell, 1988) comprised of self-states outside of one's awareness. The fact that there can be a rupture (i.e., an enactment) before a collaborative alliance is established, further highlights the conceptual problems inherent in the meaning of the alliance as a change agent (i.e., it is defined both as a prerequisite for change and developed as a goal in itself) and supports the need for ruptures as a distinct construct. As Bordin (1994) had described, unaddressed ruptures and strained alliances could lead to poor overall outcome and premature termination. This has certainly been borne out in the psychotherapy research literature (Flückiger, Del Re, Horvath, \& Wampold, 2018). However, we see how linking ruptures with alliance is confusing and conceptually limiting without the fuller appreciation of ruptures as also distinct from the alliance construct.

Jeremy integrated his background in the Buddhist tradition of mindfulness to the treatment model, providing a stance for the therapist's focus on the communication patterns as they continued to unfold (Safran, 2003; Safran \& Muran, 2000). This method of self-observation was adapted as mindfulness-in-action to help therapists position themselves as participant-observers, understanding that, to his mind, the roles were always overlapping to some extent. In other words, even while in the midst of observing and exploring the relational experience of a disagreement about a therapeutic task or goal in the hereand-now (e.g., the therapist notices a rupture marker, such as a patient begrudgingly acquiescing, and enquires about it), the therapist remains a participant in the ongoing process.

Typically, in our experiences' as clinical supervisors, a therapist's first attempts to address a rupture will lead, unintentionally, to new rupture experiences (Safran \& Muran, 2000). Perhaps the therapist has developed some clearer sense of what might be going on, after enough repeated iterations of a particular dynamic or enactment, and is aware of an increasingly strained alliance. We find that this is the part of the resolution process with which therapist trainees most struggle. Trainees are often surprised by the patient's defensive reactions in response to what is considered to be a mutative intervention (e.g., metacommunicating about the therapy process) and are frustrated by their own difficulty in seeing how they might simultaneously continue to participate in the problem while they attempt to explore it and work through it. This observation is consistent with previous research demon- strating that in the context of poor alliances, therapists who respond with more of what the treatment model advocates, such as addressing distorted cognitions in cognitive behavioral therapy (Castonguay, Goldfried, Wiser, Raue, \& Hayes, 1996) or transference interpretations in psychodynamic therapy (Piper, Azim, Joyce, \& McCallum, 1991) - without also addressing the alliance - contribute to poor overall outcome. The beginning of the rupture resolution process is particularly challenging because it requires working from within the context of a strained alliance when both the patient and therapist may feel somewhat defensive or vulnerable. Transitioning back and forth, from rupture to repair to rupture, is characteristic of the resolution process and requires the therapist to carefully track moment-to-moment shifts in the patient's and their own reactions.

Teaching this sophisticated skill to trainees became an important area of Jeremy's work more recently (EubanksCarter, Muran, \& Safran, 2015; Muran, Safran, \& Eubanks-Carter, 2010). At the time of his death, he was involved in a number of training endeavors, including initiatives at the Center for Alliance-Focused Training and the Mt. Sinai-Beth Israel Brief Psychotherapy Research Program, both in New York City (Muran, Safran, Eubanks, \& Gorman, 2018).

\section{The case of Greta}

We illustrate this complex therapeutic process with a case example of Jeremy's attempts to respond to a frustrated patient, whom we call Greta, using metacommunication to articulate his experience of her self-described manipulative behavior with others in the context of their strained alliance. Greta, a single woman in her early thirties, participated in one of our Internal Review Board approved treatment studies of time-limited Brief Relational Therapy, consenting to have data included in presentations and publications. The session segment demonstrates how Jeremy, in his early fifties at the time of this treatment, cultivates the participant-observer stance, integrating a dual focus that both increases awareness of their unfolding relational configuration and addresses their collaboration in the service of the alliance (i.e., at least an implicit agreement to continue working together in this way). The role of the therapist as a participant-observer is to utilize his or her self-observational skills, attending to personal actions, reactions, thoughts, and feelings in the momentto-moment communication with the patient, and to share those observations with the patient (rather than interpret the material) in the service of enhancing interpersonal learning (Safran \& Muran, 2000). Jeremy provided the example for us to use in classroom and workshop demonstrations of working with ruptures, however, it has not been included in any previous publications. It is challenging to find brief illustrative examples of complex negotiations that typically transpire over several sessions and 
entire treatments. We think this segment does capture an important mutative process for the patient that results from the dilemma Jeremy experiences and shares with her. He is caught between wanting to collaborate with Greta and negotiating a more authentic experience that can lead to increased awareness and a new relational experience for her.

The 7-minute segment is taken from the $16^{\text {th }}$ therapy session in a 30 -session protocol. It begins a few minutes into the session. The patient is describing a theme in her romantic relationships:

Greta: ... the same patterns would have started, he would have been a weak man, I would have been the woman in charge, the same... (patient sits forward in her chair, is gesturing a cyclical motion with her hands, and is speaking in a sing-song, rehearsed way, as if this is material she has spoken about before).

Jeremy: Mhhhmmm.

Greta: ...things that always happen in my relationships.

Jeremy: Mhhmmm.

Greta: I would have taken too much charge (patient remains sitting forward, looking therapist directly in the face, in a challenging way).

Jeremy: Mhhhmmm.

Greta: But I know this (pointing here) and the last 7 sessions, would have, have been... more a feeling of, $\mathrm{mmm}$, and....(searching for the word as she is gesturing movement with her hands).

Jeremy: I understand. So, something unexpected happened. I understand that

Greta: Unexpected? I don't know. I think that's where I was in my life, you know.

Jeremy: Yah.

Greta: That's where I am.

Jeremy: Mhhhmm, yah.

Greta: And I do want to fix these things before I go into another relationship.

Jeremy: Mhhhmmm.

Greta: I don't want to be the one in charge for the rest of my life, which, which I often am, you know.

Jeremy: Mhhhmmm.

The strained alliance is evident here. Put another way, the patient is making allusions to the negative transference that is currently enacted between them: she is both talking about the problem of being in charge as well as behaving in a controlling and critical way, and Jeremy is in the position of being the weak man. Greta is clearly frustrated with a lack of progress in the treatment.

Greta: Even here, right, I'm like constantly... when you want to say something, I interrupt you (said with a slight smile and laugh). I do things like that, right?

The patient addresses the therapeutic relationship directly, perhaps in a provocative move to push Jeremy to be more responsive but which simultaneously highlights his weak man status.
Jeremy: (Shifts in his chair) Yah, well...you're, you're making a kind of...it's a complicated thing, because you're asking me to be more in charge, really, is the issue, right? In some ways.

Jeremy makes a first attempt to articulate his experience with Greta, metacommunicating his dilemma in an effort to disembed from the particular toxic relational configuration that is being enacted. He is struggling to find the right words.

Greta: Yah. And if you are, I'm like, great! (slumps down in her chair, her arms dangling over the sides of the chair in an exaggerated demonstration of relief).

Jeremy: Uhum.

Greta: But it's a pattern.

Jeremy has her attention here but she remains in charge.

Jeremy: It's a kind of a...It's a paradoxical thing, right (therapist is making a back and forth motion with his right hand)...

Greta: Yah.

Jeremy: Because you're, you're asking $m e$ to be in charge, you know, (therapist moves forward in his chair towards the patient) and you really have been from the beginning.

Greta: Hmmm.

Jeremy: Right? But in my doing that, I feel like, ah, in a sense like I am not really being in charge. I am doing what you are telling me what to do. Do you, do you understand?

Greta: That's a very typical pattern for me, yah...

The patient's voice is much softer in her response to his metacommunication as she shifts her focus from external to internal. It seems that Jeremy has touched on something that is a core issue for her. His description of his experience is non-blaming, which may be why she is softer in her response and able to begin to explore her own experience.

Jeremy: Mhhmmm.

Greta: That's exactly what happened with me and Franco.

Jeremy: Mhhmmm.

Greta: I think in a way I am imitating my father. My father is this supercharged, like super.... This man was always in charge, has been that way all his life. At the same time, I think all he was looking for was someone who would take some of that, you know.

This reveals an aspect of the patient's internal working model of relationships and what she expects could happen with Jeremy: if he took charge, she would be free of this burden. However, it is also a movement away from the intensity of the here-and-now exploration, reverting back to an external focus. In directing her attention to other relationships, Greta has subtly withdrawn from the task of exploring her impact on Jeremy and her experience of his comments. Her voice quality has reverted back to externalizing, with a high energy level. 
Jeremy: Mhhmmm.

Greta: I think now at the end of his life he is very lonely and sad...

Jeremy: Mhhmmm.

Greta: .... and depressed, because he has no real relationship with anybody...

Jeremy: Right...

Greta: ...because he was so in charge the whole time and everybody always had to do what he said.

Jeremy: Right...

Greta: And somehow, I feel I am imitating his behavior a lot.

Jeremy: Mhhmmm.

Greta: This strong person who always knows exactly what to do... has all the answers. Everybody has to do everything he says.

Again, these are associations related to the theme of how empty she and her father feel being the ones in charge, but they are considered subtle withdrawal markers because they are shifts away from the task of exploring the here-and-now of the therapeutic relationship.

Jeremy: Right. Well, that's a real dilemma, you know, for you and for us right now, right, in a sense, how to... because here you are, you desperately want me to be more in charge in the time we have left, right, and yet I can't, there is a way in which I can't in response to your demand, in some way, you know? Do, do you understand?

Jeremy has made another attempt at metacommunicating about the experience in the here-and-now, re-directing the focus back to their intersubjective negotiations.

Greta: Do you feel like it is because I don't let you or you think my demand is so big? (patient's voice has softened here, she takes a drink of water from her water bottle).

Here, Greta accepts Jeremy's invitation to explore their relationship directly but she does so in her characteristic in charge style: she has given him only two options for a response.

Jeremy: Mhhhmm, that's a good question...ummm... hmmm...I don't feel like it's because you don't let me. No. I don't think it's that. Ummm, do I feel it's because your demand is so big?... Ummm...

The tentativeness with which Jeremy is unpacking this experience is a guiding principle of mindfulness-in-action. The interpersonal implications of his decision to repeat her question are interesting. It seems to reflect how he is grappling with the tension between remaining engaged in the exploration of the experience (i.e., identifying the rupture from his stance as a participant in the enactment) and simultaneously positioning himself as somewhat outside of the field (i.e., as a participant-observer), also responding to her questions in a way that addresses the alliance (i.e., he wants to give her what she is asking for as it would likely increase their collaboration and strengthen their bond).

Greta: Or it's, maybe...it's not within your capacity? (patient fiddles with cap of water bottle)

The patient is engaged with this exploration and is a little less controlling here, a little more tentative herself, giving Jeremy slightly more room to respond autonomously. However, her style remains one of providing Jeremy with limited fixed choices.

Jeremy: It's two things, I guess. Number 1 ...I feel like you are asking me to do something, to be, to do something that doesn't really fit with my personality, you know, to structure things that much. Is part of it, right? And so, well, then I think, "why can't I try to do that, if that is what she asking me to do," but then I start to feel resentful because I am twisting myself into something I am not.

Jeremy makes yet another attempt at describing his experience with Greta and his dilemma with her. The word resentful is powerful and he may have chosen to use it because Greta was not fully grasping what he was saying in his first efforts to metacommunicate his experience. He again shifts to addressing the alliance and emphasizes a potential collaboration ("why can't I do that if that is what she is asking me to do"). He is expressing that he has considered giving her what she is asking for as well as explaining why he cannot.

Greta: Is it really about you, or is it about...it's interesting how you say that, as if it is about you as a person. Isn't it about you as a professional, or...?

Jeremy: But they overlap.

Greta: Really. In this form of therapy, is it about me taking charge of my own life and being responsible for my life and...?

Greta seems both intrigued but also confused about how this intervention might help her. She is organized around the experience and theme of being in charge.

Jeremy: No, I don't think it's that. I really think it is about what I am saying, as best as I can tell. It's that...

Greta: That's really interesting, "cause I think a lot of people in my life often feel manipulated by me. You know, in that same way, like...(several seconds of silence).

Jeremy: It's hard because I find myself, on the one hand, wanting to give you what you are asking for. It doesn't seem unreasonable...Umm, and then on the other hand, I start to feel resen...In order to do that I start to feel like I would be twisting myself into...

Greta: You feel manipulated, in a way.

This statement, while presented as a declarative rather than a question, is also made in a relatively softer voice and the added in a way suggests she is more open to there being other possibilities. Jeremy is working hard to remain in the here-and-now exploration while being pulled to respond to her demands. If he went along with her, he would be complying rather than truly negotiating a new and positive shift in their working relationship. Greta's awareness of this paradoxical aspect of the dynamic, that her demands set Jeremy up to occupy the weak man status, is emerging.

Jeremy: (moving his head from side to side as if pondering the patient's statement) Yah (pause). I guess. 
Greta: Interesting...I guess that is how a lot of people feel around me.

There were a few iterations of this shifting between Jeremy metacommunicating about his authentic experience with Greta, in the service of deepening her experience of herself in this relationship (i.e., highlighting the paradoxical nature of the in charge aspect of her character), and his directly addressing the disagreement about a particular task of therapy, an aspect of their collaborative alliance. There were moments when Greta could stay connected to Jeremy as they tentatively explored their intersubjectivities in the here-and-now, and this seemed to be a new relational (corrective emotional) experience for her. Elements of her characteristic, manipulative style are, of course, still evident but they are shifting too.

\section{Conclusions}

\section{Resolving dialectics}

In closing, we underscore how understanding the theme of ambivalence in Jeremy's work and approach to the alliance is ultimately to recognize the various dialectics he tried to negotiate: self and object, agency and communion, implicit and explicit, to highlight a few. He saw mindfulness and metacommunication as methods that had the potential to resolve these dialectics, but of course he came to be ambivalent about their potential, as well. One could say he was, at heart, postmodern in sensibility: pluralistic - reflexive and constructive - ever evolving.

\section{References}

Aron, L. (1996). A meeting of minds: Mutuality in psychoanalysis. Hillsdale, N.J.: Analytic Press.

Balint, M. (1968). The basic fault. London: Tavastock.

Benjamin, J. (1990). An outline of intersubjectivity: The development of recognition. Psychoanalytic Psychology, 7, 33-46.

Bordin, E. (1979). The generalizability of the psychoanalytic concept of the working alliance. Psychotherapy, 16, 252-60.

Bordin, E. (1994). Theory and research in the therapeutic working alliance: New directions. In: A. O. Horvath \& L. S. Greenberg (Eds). The working alliance: Theory, research, and practice (pp. 12-37). New York, NY: Wiley.

Castonguay, L., Goldfried, M. R., Wiser, S., Raue, P. J., \& Hayes, A. M. (1996). Predicting the effect of cognitive therapy for depression: A study of unique and common factors. Journal of Consulting and Clinical Psychology, 64(3), 497504.

Eubanks-Carter, C., Muran, J. C., \& Safran, J. D. (2015). Alliance-focused training. Psychotherapy, 52(2), 169-173.

Flückiger, C., Del Re, A. C., Horvath, A. O., \& Wampold, B. E. (2018). The alliance in adult psychotherapy: A meta-analytic synthesis [APA Task force]. Psychotherapy, 55(4), 316-340.

Freud, A. (1936). The ego and mechanisms of defense. New York: International Universities Press.

Freud, S. (1912/1958). The dynamics of transference. In Stan- dard edition (vol. 12, pp. 97-108). London: Hogarth Press. Greenberg, L.S., \& Safran, J.D. (1987). Emotion in psychotherapy. New York, NY: Guilford.

Greenson, R. (1967). The technique and practice of psychoanalysis. New York, NY: International Universities Press.

Hartmann, H. (1958). Ego psychology and the problem of adaptation. New York: International Universities Press.

Hatcher, R.L. (2010). Alliance theory and measurement. In J.C. Muran \& J.P. Barber (Eds.), The therapeutic alliance: An evidence-based guide to practice (pp. 7-28). New York, NY: Guilford.

Levenson, E. (1992). The purloined self: Interpersonal perspectives in psychoanalysis. New York: Contemporary Psychoanalysis Books.

Mitchell, S. A. (1988). Relational concepts in psychoanalysis. Cambridge, MA: Harvard University Press.

Muran, J. C., Safran, J. D., \& Eubanks-Carter, C. (2010). Developing therapist abilities to negotiate alliance ruptures. In J. C. Muran \& J. P. Barber (Eds.), The therapeutic alliance: An evidence based guide to practice (pp. 320-340). New York: Guilford.

Muran, J. C., Safran, J. D., Eubanks, C. F., \& Gorman, B. S. (2018). The effect of alliance-focused training on a cognitive behavioral therapy for personality disorders. Journal of Consulting and Clinical Psychology, 86(4), 384-397.

Muran, J. C., Segal, Z. V., Samstag, L. W., \& Crawford, C. (1994). Patient pretreatment interpersonal problems and therapeutic alliance in short-term cognitive therapy. Journal of Consulting and Clinical Psychology, 62(1), 185-190.

Piper, W. E., Azim, H. F., Joyce, A. S., \& McCallum, M. (1991). Transference interpretations, therapeutic alliance, and outcome in short-term individual psychotherapy. Archives of General Psychiatry, 48(10), 946-53.

Pizer, S. A. (1998). Building bridges: The negotiation of paradox in psychoanalysis. Hillsdale, N. J.: Analytic Press.

Safran, J. D. (1984a). Assessing the cognitive-interpersonal cycle. Cognitive Therapy and Research, 8, 333-348.

Safran, J. D. (1984b). Some implications of Sullivan's interpersonal theory for cognitive therapy. In M. A. Reda \& M. J. Mahoney (Eds.), Cognitive psychotherapies: Recent developments in theory, research and practice. Cambridge, MA: Ballinger.

Safran, J. D. (1990a). Towards a refinement of cognitive therapy in light of interpersonal theory: I. Theory. Clinical Psychology Review, 10, 87-105.

Safran, J. D. (1990b). Towards a refinement of cognitive therapy in light of interpersonal theory: II. Practice. Clinical Psychology Review, 10, 107-121.

Safran, J. D. (1993). Breaches in the therapeutic alliance: An arena for negotiating authentic relatedness. Psychotherapy: Theory, Research, Practice, and Training, 30(1), 11-24.

Safran, J. D. (2003). The relational turn, the therapeutic alliance and psychotherapy research: Strange bedfellows or postmodern marriage? Contemporary Psychoanalysis, 39, 449475.

Safran, J. D., Crocker, P., McMain, S., \& Murray, P. (1990). The therapeutic alliance rupture as a therapy event for empirical investigation. Psychotherapy: Theory, Research, Practice, Training, 27, 154-165.

Safran, J. D., \& Muran, J. C. (1996). The resolution of ruptures in the therapeutic alliance. Journal of Consulting \& Clinical Psychology, 64, 447-458.

Safran, J. D., \& Muran, J. C. (2000). Negotiating the thera- 
peutic alliance: A relational treatment guide. New York, NY: Guilford.

Safran, J. D., \& Muran, J. C. (2006). Has the concept of the alliance outlived its usefulness? Psychotherapy: Theory, Research, Practice, Training, 43, 286-291.

Safran, J. D., Muran, J. C., \& Samstag, L. W. (1994). Resolving therapeutic alliance ruptures: A task analytic investigation. In A. O. Horvath \& L. S. Greenberg (Eds.), The working alliance: Theory, research, and practice (pp. 225-255). New York, NY: Wiley.

Safran, J. D., Muran, J. C., Samstag, L. W., \& Stevens, C. (2002). Repairing alliance ruptures. In J.C. Norcross (Ed.), Psychotherapy relationships that work (pp. 235-254). New York: Oxford University Press.

Safran, J. D., \& Segal, Z. V. (1990/1996). Interpersonal process in cognitive therapy. New York: Basic Books. $\left(2^{\text {nd }}\right.$ ed. Northvale, N.J.: Aronson).

Safran, J. D., \& Wallner, L. K. (1991). The relative predictive validity of two therapeutic alliance measures in cognitive therapy. Psychological Assessment: A Journal of Consulting \& Clinical Psychology, 3(1), 22-37.

Sterba, R. (1934). The fate of the ego in analytic therapy. International Journal of Psycho-Analysis, 15, 117-126.

Sterba, R. (1940). The dynamics of the dissolution of the transference resistance. Psychoanalytic Quarterly, 9, 363-379.

Stern, D. B. (1997). Unformulated experience. Hillsdale, N.J.: Analytic Press.

Strupp, H. H. (1980). Success and failure in time-limited psychotherapy: further evidence (Comparison 4). Archives of General Psychiatry, 37(8), 947-954.

Strupp, H. H., \& Hadley, S. W. (1979). Specific vs nonspecific factors in psychotherapy: A controlled study of outcome. Archives of General Psychiatry, 36(10), 1125-1136.

Winnicott, D. W. (1965). The maturational process and the facilitating environment. New York; International Universities Press. 